\title{
Monitoring Land Suitability for Mixed Livestock Grazing Using Geographic Information System (GIS)
}

\author{
Fazel Amiri, Abdul Rashid B. Mohamed Shariff and Taybeh Tabatabaie
}

Additional information is available at the end of the chapter

http://dx.doi.org/10.5772/47939

\section{Introduction}

Combining land and land use in a land evaluation procedure defines land suitability, which is the fitness of a land unit for a land use type assessed by comparing land use requirements of each land utilization type with the land (FAO, 1976; 2007). Land suitability analysis is an important tool in making locational and sitting decisions in planning studies. Broadly defined, land-use suitability analysis aims at identifying the most appropriate spatial pattern of future land use according to specified requirements, preferences, and predictors of specific activities (Collins, Steiner, Rushman, 2001; Hopkins, 1977).

In Ghara-Aghch region, center Iran, the need for rangeland suitability evaluation is due to increasing livestock population, which causes an increased demand for forage. In This area, livestock and pasture is a very important business for the community to sustain living. Livestock (Sheep and goats) are fed from pasture. Land management, therefore, is a real issue that requires proper attention from the authorities to ensure sustainability of the rangeland sector in the state. The regeneration rate of rangeland resources is very slow, so it is not able to cope with the ever increasing livestock population growth; hence this imbalance situation leads to regional economic development problems. Proper evaluation based on land planning is essential to solve this problems (Sonneveld, Hack-ten Broeke, van Diepen, Boogaard, 2010).

Definition of the term "mixed livestock grazing" was first used in rangeland forage grazing of livestock by Cook (1954) and subsequently by Smith (1965). They defined the term "mixed livestock grazing" as the use of a pasture's forage for more than one variety of livestock (cattle, sheep and goats) with the aim of achieving maximum productivity. Holechck et al. (1995) explained the rationale for stability improvement of rangelands against the mixed 
livestock grazing as follows: better distribution of livestock in the pasture, harvesting more than one plant species, and more uniform use of pasture lands. In terms of the economy of the rangeland, "mixed livestock grazing" can be studied in three aspects: firstly, with 'mixed livestock grazing' there is an increase in livestock products and the income will increase; secondly, the risk hazard will decrease; and thirdly, the invading species will be controlled. On the other hand, with "mixed livestock grazing" the preservation costs will increase, and rangeland management becomes more difficult (Coffey, 2001). Heady (1975) reported that with mixed livestock grazing, the efficiency of forage use will increase due to combined use of the grasses, forbs, and shrubs. However, Smith (1965) observed that topography, water resources, and priority of management goals are among the factors determining the success or failure of management of "mixed livestock grazing" rangelands. Coffey (2001) noted that selective grazing species by the livestock in 'mixed livestock grazing' is very important. The cattle prefer grasses to the forbs and shrubs, while the sheep prefer the forbs to the grasses and the goats prefer the shrubs and small branches compared to the grasses and forbs. Therefore, the common grazing of cattle, sheep and goats on rangelands results in all vegetation being grazed and as a result the woody plants and shrubs which form a large part of the rangeland will be grazed in large quantities with common grazing. Luginbuhl et al. (2000) observed that by adding goats to a pasture being grazed by cattle showed a decrease in shrubs and provision of sufficient time for regeneration of the grasses. In fact, by adding the goats to the pasture grazed by the cattle controlled woody plants without influencing the cattle's grazing preference, and thus grazing capacity was increased with a rise in income. Adding the sheep in a pasture which is being grazed by the cattle showed similar results, although sheep in comparison with goats consume fewer woody species; however, the sheep can be used to control the woody species with suitable grazing pressure and thus cause an improvement in the rangeland. Several studies have reported model suitability of the rangelands for livestock grazing (Alizadeh, Arzani, Azarnivan, Mohajeri, Kaboli, 2011; Amiri, 2009a; b; Arzani, Jangjo, Shams, Mohtashamnia, Fashami, Ahmadi, Jafari, Darvishsefat, Shahriary, 2006; Bizuwerk, Peden, Taddese, Getahun, 2005; Gavili, Ghasriani, Arzani, Vahabi, Amiri, 2011; Javadi, Arzani, Farahpour, Zahedi, 2008; Thornton, Herrero, 2001). The allocation of limited rangeland resources to various land uses, lack of sufficient environmental policies for sustainable use of rangelands as well as degradation of these areas have caused increasing concern among managers and revealed the importance of land suitability analysis. However, no research has been reported on the mixed livestock grazing of sheep and goats. Therefore, the objectives of this study, while recognizing important factors affecting model suitability for 'mixed livestock grazing' of the rangelands, was also designed to determine the kind and rate of the limitations and factors reducing the suitability for an adequate plan for grazing.

As complexity of decisions increases, manual processes become time consuming and are liable to errors, resource managers may increasingly lack the necessary expertise, and, therefore, capacity to make resource management decisions that integrates the range of issues involved. One of the reasons is that the decision may be based on very little information. Other reasons may be the lack of module with flexible user interface (Barbari, Conti, Koostra, Masi, Guerri, Workman, 2006). 
A number of technological developments have facilitated the implementation of land evaluation principles and models. In order to incorporate the different land attributes that differ spatially and to identify the best suitable land use, GIS has proved to be the best tool (Bizuwork, Taddese, Peden, Jobre, Getahun, 2006). The powerful query, analysis and integration mechanism of GIS makes it an ideal scientific tool to analyze data for land use planning. Management of natural resources based on their potential and limitation is essential for development of rangeland on a sustainable basis. GIS technology is being increasingly employed by different users to create resource database and to arrive at appropriate solutions/strategies for sustainable development of rangelands (Venkataratnam, 2002). Today, GIS is a tool that can assist a community to plan and to support the information management during the rangeland production process, while at the same time ensures the proper balance between competing resource values. It can enhance the accessibility and flexibility of information and can improve the linkages and understanding of relationship between different types of information (Baniya, 2008).

\section{Methodology}

\subsection{Study area}

The study area is located in the Ghara-Aghch catchment in Isfahan province (10 kilometers northeast of Semirom), in the central part of Iran. The area under study (51 ${ }^{\circ}, 34^{\prime}, 54^{\prime \prime}$ to $51^{\circ}$, $45^{\prime}, 53^{\prime \prime} \mathrm{E}$ and $31^{\circ}, 26^{\prime}, 19^{\prime \prime}$ to $31^{\circ}, 03^{\prime}, 28^{\prime \prime} \mathrm{N}$ ) comprises of 8962.25 -hectares of which $79.9 \%$ is rangeland (Figure.1). The climate is semi-arid with an average annual rainfall of $358 \mathrm{~mm} \mathrm{yr}$ 1 , falling mainly in the autumn and winter. The average minimum and maximum temperatures are 3.1 and $16.7^{\circ} \mathrm{C}$, respectively. The Mean annual temperature is about 10 degrees Celsius) and the climate based on the classification using the Dumbarton method is semi-arid. Sheep and goats were the two main sources of animal production. In GharaAghch, the rangeland area is negatively affected by inappropriate land management practices, e.g. over utilization. Uncontrolled utilization of the vegetation of the rangelands affects forage quality because of the transition from a plant community with a higher nutritive value to one with lower nutritional value.

\subsection{Vegetation type}

Site evaluation and data collection was carried out during the spring until autumn of 2010. Vegetation segments, pasture boundaries, agricultural lands, fruit gardens, urban settlements, bare soils, out cropped rocks and stony areas were mapped in field studies using 1:50,000 scale map and aerial photographs. Preliminary vegetation types were distinguished with the physiognomic-floristic-ecologic method. Meanwhile with the determination of the pasture types, the boundaries were checked on the map according to the features of vegetation entities and dominant species. In this study, a visual scoring method of the available dominant species was used to report the vegetation cover map, botanical composition, and forage production in 17 vegetation types (Figure2; Table1). Overstocking and extended grazing periods are characteristics of inappropriate 


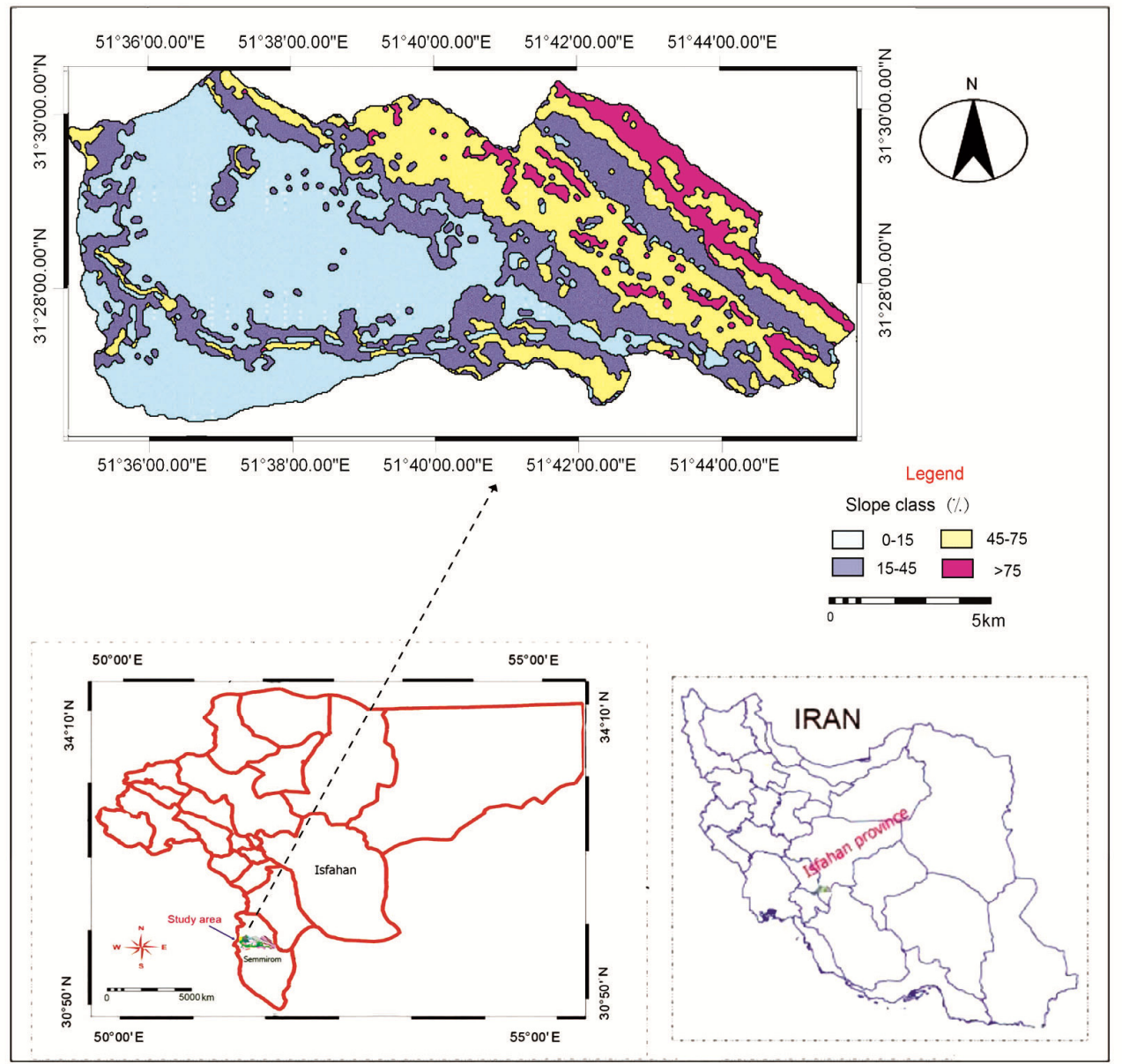

Figure 1. Location of study area within the Ghara-Aghch District

management practices in the study area. In this study, 182 plant species in ten major vegetation types were identified in the rangelands in Ghara-Aghch showing negative and poor trends and conditions. 


\begin{tabular}{lrl}
\hline No. & Abbreviations Vegetation type & Area (ha) \\
\hline 1 & Ag.tr Agropyron trichophoum & 122.77 \\
2 & Ag.tr-As.pa Agropyron trichophoum-Astragalus parroaianus & 305.59 \\
3 & Ag.tr-As.ca-Da.mu Agropyron trichophoum-Astragalus canesens-Daphne macronata & 898.36 \\
4 & As.ad-Ag.tr-Da.mu Astragalus adsendence-Agropyron trichophoum-Daphne macronata & 385.59 \\
5 & As.pa-Ag.tr Astragalus parroaianus-Agropyron trichophoum & 162.77 \\
6 & As.ly-Ag.tr-Da.mu Astragalus lycioides-Agropyron trichophoum-Daphne macronata & 237.51 \\
7 & As.ca-Br.to-Co.cyl Astragalus canesens-Bromus tomentellus-Cousinia cylianderica & 2029.68 \\
8 & As.br-Br.to-Da.mu Astragalus brachycalyx-Bromus tomentellus-Daphne macronata & 116.2 \\
9 & As.go-Co.cyl Astragalus gossipianus-Cousinia cylanderica & 362.66 \\
10 & As.pa-Co.cyl-Da.mu Astragalus parroaianus-Cousinia cylanderica-Daphne macronata & - \\
11 & As.cy-Fe.ov Astragalus cyclophylus-Ferula ovina & 105.7 \\
12 & Br.to-As.pa Bromus tomentellus-Astragalus parroaianus & 373.11 \\
13 & Co.ba-As.go Cousinia bachtiarica-Astragalus gossipianus & 188.52 \\
14 & Co.ba-Sc.or Cousinia bachtiarica-Scariola orientalis & 499.07 \\
15 & Fe.ov-Br.to-As.za Ferula ovina-Bromus tomentellus-Astragalus zagrosicus & 212.33 \\
16 & Ho.vi-Po.bu Hordeum bulbosum-Poa bulbosa & 36.76 \\
17 & Br.to-Sc.or Bromus tomentellus-Scariola orientalis & 153.58 \\
\hline Total rangeland area & 7158.81 \\
\hline
\end{tabular}

Table 1. Vegetation communities in Ghara-Aghch rangelands

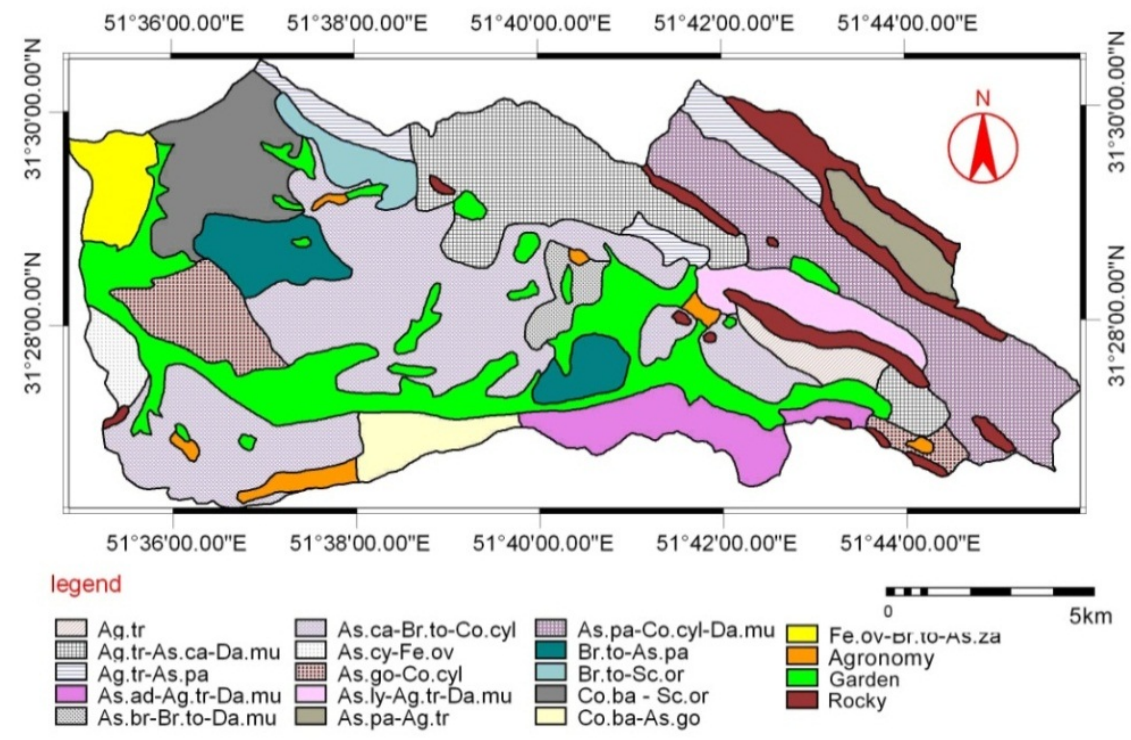

Figure 2. Vegetation type (VT) of Ghara-Aghch rangelands

\subsection{Factors of livestock model}

The livestock grazing model suitability comprises of three measures: the capacity and production of forage, the soil sensitivity to erosion, and physical factors (water resources 
and slope). The components of the suitability model for livestock grazing are illustrated in Figurer 3.

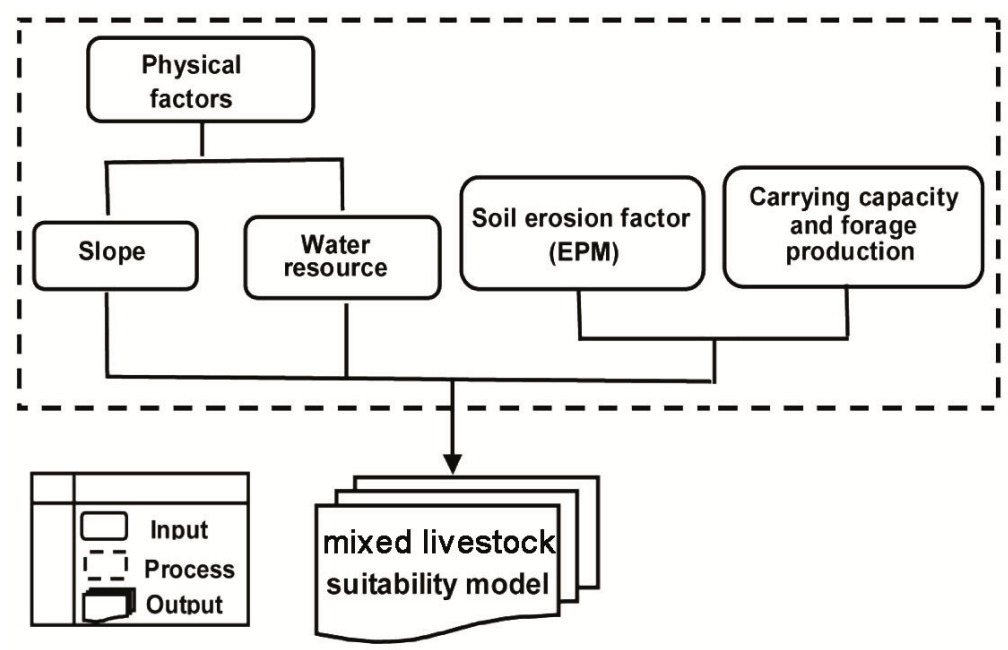

Figure 3. Components of mixed livestock grazing suitability model

The method introduced by FAO (1991) for range suitability classification used ILWIS version 3.6 as the GIS Software. Land evaluation normally requires a comparison between the inputs required and the outputs obtained when each relevant land utilization type is applied to each land unit.

Two orders of range suitability for livestock grazing were considered: suitable (S) or unsuitable (N). Three classes of suitability were determined: highly suitable (S1), moderately suitable (S2), and marginally suitable (S3) (FAO, 1976; 1983; 1984; 1985; 1991; 2002; 2007).

\subsection{Soil sensitivity to erosion}

Soil sensitivity to erosion was determined by the Erosion Potential Model (EPM). This model was based on the evaluation of the four factors of land use, slope, erosion potential, soil characteristics, and geology, depending on the strength and weakness of each factor (Ahmadi, 2004; Rafahi, 2004). Figurer 4 illustrates the suggested factors and their relationships in this model (Amiri, 2010). The slope map and EPM model were used to calculate erosion potential and create erosion sensitivity classes.

According to this model:

$$
Z=Y . X a(\Psi+I 0.5)
$$

where, $\mathrm{Z}$ is the erosion severity index, $\mathrm{Y}$ is the sensitivity of soil and bedrock to erosion, $\mathrm{Xa}$ Is the land use index, $\Psi$ is the erosion index of the watershed, and $I$ is the average gradient of the slope (Amiri, 2010). 
Soil depth, type, texture, gravels, structure, rocky outcrops, and groundwater were the characteristics used to categorize each group (Figure 4). Sensitivity to erosion in the submodel for each vegetation type was created and classified by integrating range condition, land use, slope, erosion potential, soil characteristics, and geology (Table 2). The lower erosion class was placed in suitability category S1, low and medium erosion class in S2 suitability category and high and very high erosion classes were placed in the suitability categories of $\mathrm{S} 3$ and $\mathrm{N}$ respectively (Table 2).

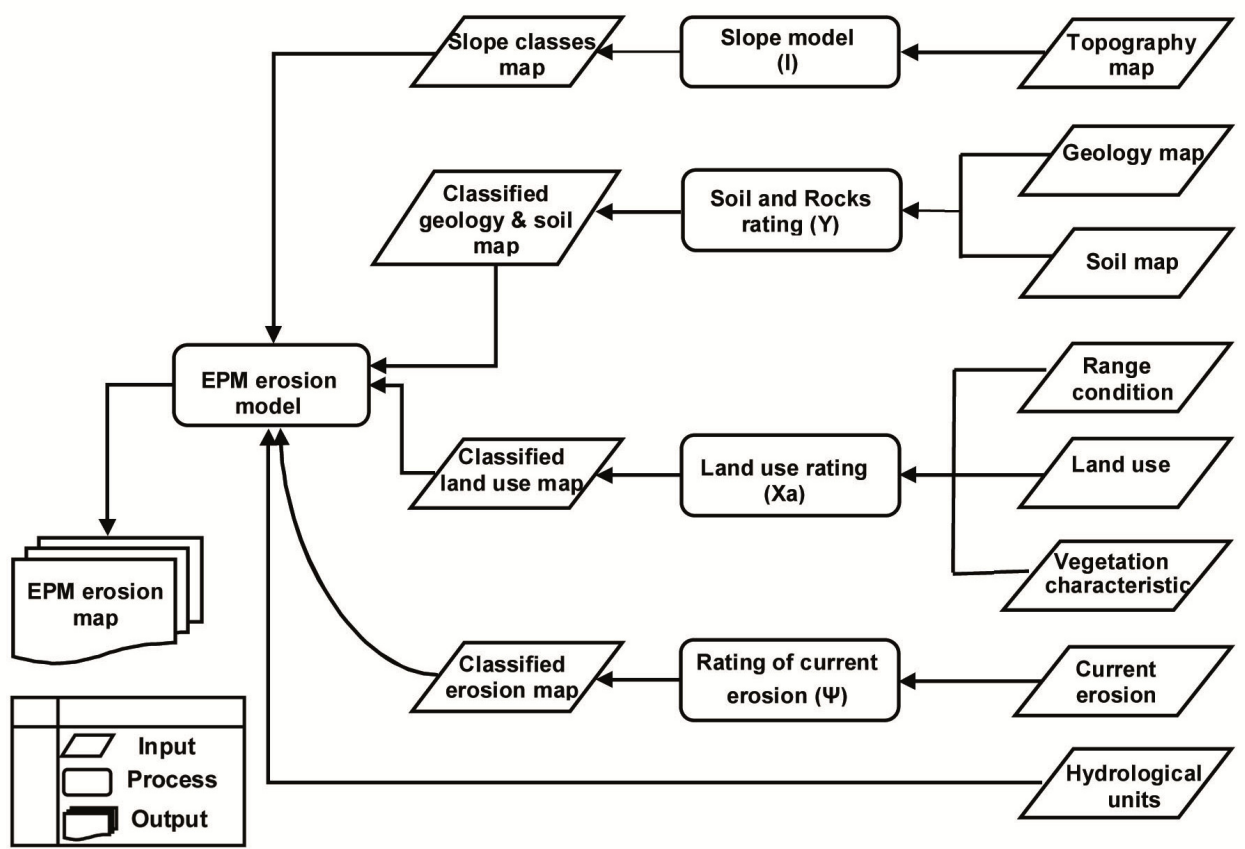

Figure 4. EPM model for soil erosion

\begin{tabular}{llll}
\hline Symbol & Range of $Z$ & classes & Suitability classes \\
\hline 1 & $<0.2$ & Low & S1 \\
2 & $0.2-0.7$ & Medium & S2 \\
3 & $0.7-1$ & High & S3 \\
4 & $>1$ & Very High & N \\
\hline
\end{tabular}

Table 2. Classes of sensitivity to erosion (Amiri, 2009a)

\subsection{Grazing capacity and forage production factors}

In terms of data relevant to the conditions of livestock breeding, the percentile herd combination in each Samman unit [In Iranian rangelands, the livestock can only use water in Samman unit] was used to determine the livestock grazing capacity (Amiri, 2009b). First the Samman unit plan was adopted with the vegetation types of the region so that the percentile 
of the herd combination in the vegetation types located in the boundaries of each Samman unit could be determined. The vegetation parameters recorded in April-May and May-June 2009 and April-May and May-June 2010 were used in the study.

The grazing capacity and the suitability of the forage production in vegetation types was first determined. The existing plant species in the vegetation types were listed and the percentage of canopy cover of each variety was determined separately based on the percentage derived from total plots sampled. The production of entire plant varieties edible to sheep and goats were separately determined by cutting and weighing of samples in each plot at the end of the active growth period (Milner, Hughes, Gimingham, Miller, Slatyer, 1968). Samples were taken at random in the 10 vegetation types (determined via floristicphysiognomic method) within one-square-meter plots with three 200-meter transects. Based on field visits and interviews with experts from the Natural Resources Institute (NRI) the palatability classes of the species separately for sheep and goats were classified into one of the three palatability classes (I, II, and III) and the proper use factors (PUF) in vegetation types were determined based on the soil sensitivity to erosion suitability class adapted from the EPM model with respect to the range conditions and range trends in vegetation types (Table 3).

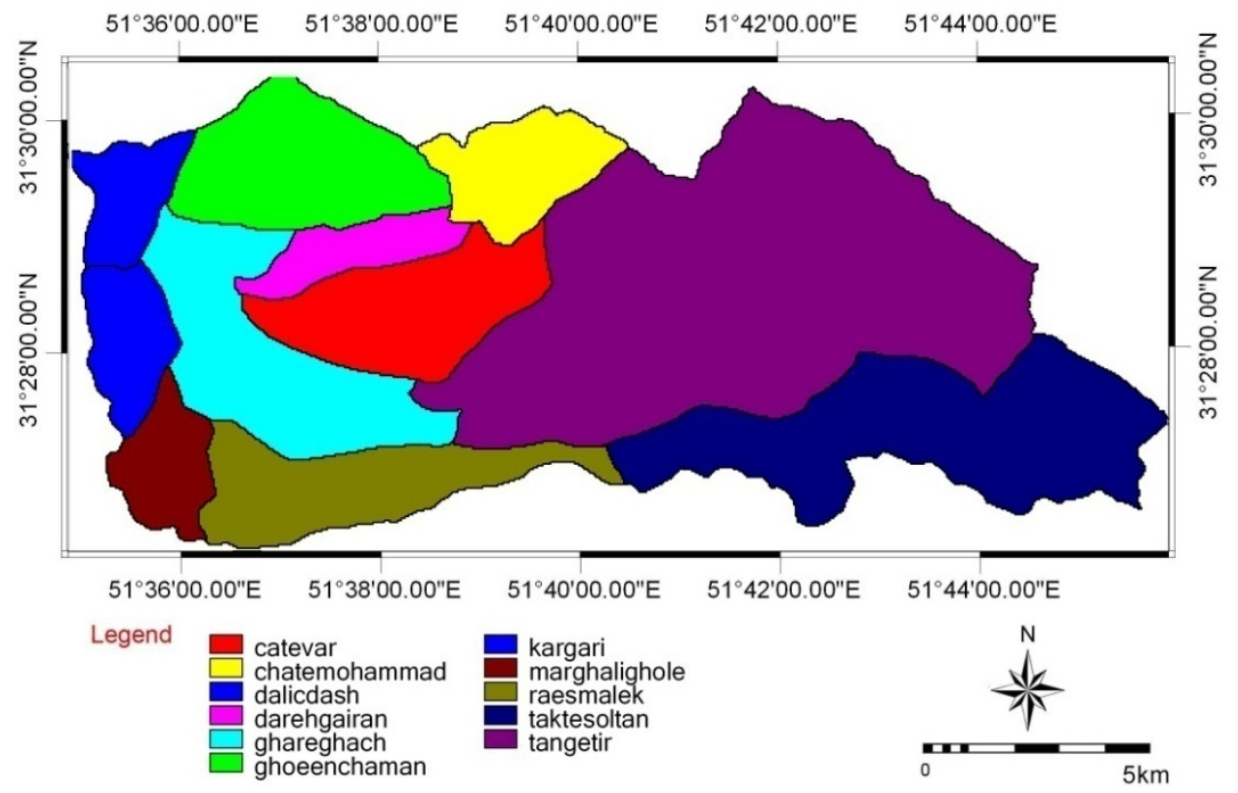

Figure 5. Utilization units in Ghara-Aghch rangeland

Then the available forage of the existing varieties in the vegetation types for sheep and goats in livestock use was calculated from the product of palatability or Proper Use Factor (PUF) (each one, which is lesser) of each variety and herd combination percentage (sheep and goats) and by adding up the available forage products of all varieties of a type (Smith, 1965). 
Figurer 6 illustrates the components of capacity and suitability of forage production for livestock use. The diagram derived from the livestock grazing capacity model will then be applied in the next stage as input for the water resource model.

\begin{tabular}{|c|c|c|c|}
\hline $\begin{array}{lll}\text { Soil } & \text { Erosion } & \text { sensitivity } \\
(\mathrm{SE}) & & \\
\end{array}$ & Range condition (RC) & Range trend (RT) & $\begin{array}{l}\text { Proper Use Factor } \\
\text { (PUF) }\end{array}$ \\
\hline Low and Medium (S1 or S2) & Good or Excellent & Up or Static & 50 \\
\hline Low and Medium (S1 or S2) & Good or Excellent & Down & 40 \\
\hline Low (S1) & Fair & Up or Static & 40 \\
\hline Medium (S2) & Fair & Up or Static & 35 \\
\hline Medium (S2) & Fair & Down & 30 \\
\hline High (S3) & Fair & Up or Static & 30 \\
\hline High (S3) & Fair & Down & 25 \\
\hline Medium (S2) & Poor & Up or Static & 30 \\
\hline Medium (S2) & Poor & Down & 25 \\
\hline High (S3) & Poor & Up or Static & 25 \\
\hline High (S3) & Poor & Down & 20 \\
\hline
\end{tabular}

Table 3. Palatability coefficients and proper use factor rates used in the calculation of available forage [When the erosion suitability class is S3 and the pasture is in a poor condition and the tendency is negative, the allowed exploitation limit for goats is considered zero and the production suitability class is considered $\mathrm{N}$ (unsuitable)] (Amiri, 2009a)

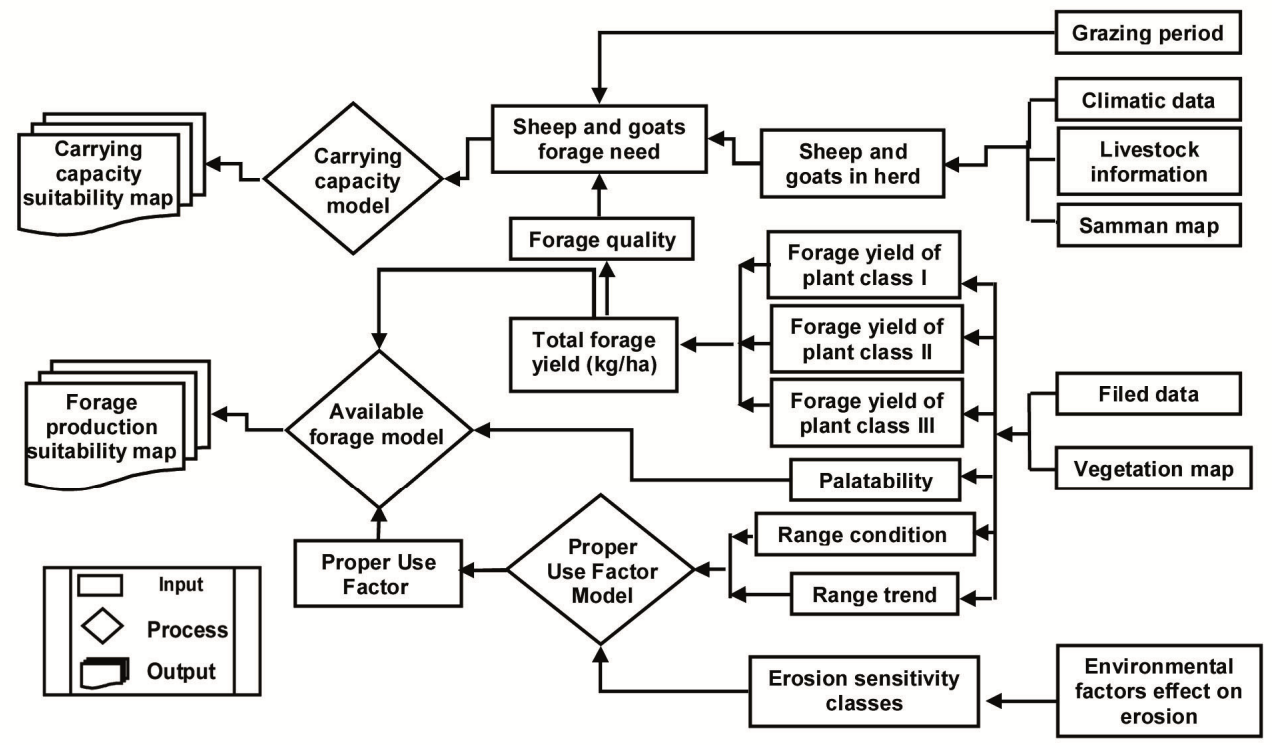

Figure 6. Components of carrying capacity and suitability of forage production in livestock use model 
As illustrated in Figurer 6 the components of the livestock grazing capacity model comprises of four sub-models which include the amount of available forage for the sheep and goats, gazing period, forage needed for livestock use, and the area of the vegetation types (ha). In order to create the available forage, the relevant information was integrated for each vegetation type using Equation 2:

$$
\mathrm{DLNN}=\mathrm{GP}+\mathrm{T}+\mathrm{FQ}
$$

where, DLNN = Daily Livestock Nutrition Need, GP = Grazing Period, $\mathrm{T}=$ Topography, and FQ = Forage Quality (Amiri, 2010a).

The average daily requirement of a $50 \mathrm{~kg}$ sheep and $37 \mathrm{~kg}$ goat consuming quality forage was determined as $1.35 \mathrm{~kg}$ dry matter. Available forage (AF, $\mathrm{kg} /$ day) for livestock was calculated as:

$$
\mathrm{AF}=\Sigma(\mathrm{Y}+(\mathrm{P} / \mathrm{PUF}))
$$

where; $\mathrm{Y}=$ yield $(\mathrm{kg} / \mathrm{ha}), \mathrm{P}=$ palatability, and $\mathrm{PUF}=$ proper use factor (Guo, Liang, Liu, Niu, 2006); while PUF was determined by combining information on trends in range condition and erosion sensitivity (Amiri, Shariff, 2011).

The livestock grazing capacity model as described earlier comprises of four sub-models which include the amount of available forage for the sheep and goats, gazing period, forage needed for the sheep and goats, and the area of the vegetation types. The grazing capacity was calculated using Equation 4 (Guo, Liang, Liu, Niu, 2006).

$$
\mathrm{GC}=\frac{\mathrm{AF}}{\mathrm{DLNN}}
$$

where GC id the for grazing capacity, AF is the available forage $(\mathrm{Kg} / \mathrm{ha})$ in the area (ha), and DLNN is the Daily Livestock Nutritional Need (Amiri, 2009a). The number of goats was determined using the Animal Unit (A.U) for goats as 0.8. The forage production suitability class, based on the ratio of the available forage production to the total products of that type was determined from Table 4 .

\begin{tabular}{clc}
\hline State & Available forage production $(\mathrm{AF})^{*}$ & Production classes \\
\hline 1 & $\% 40$ (of total production) & $\mathrm{S} 1$ \\
2 & $\% 30-40$ (of total production) & $\mathrm{S} 2$ \\
3 & $\% 20-30$ (of total production) & $\mathrm{S} 3$ \\
4 & $<\% 20$ (of total production) & $\mathrm{N}$ \\
\hline
\end{tabular}

Table 4. Forage production suitability classes [ ${ }^{*}$ Minimum production lower then $\left.100(\mathrm{~kg} / \mathrm{h})\right]$

\subsection{Physical factors}

The suitability class of this model was determined via the combination of the two measures of slope and water resources. 


\subsection{Slope}

The slope suitability categories in livestock use were determined from the slope suitability classes (Table 5).

\begin{tabular}{lcccc}
\hline Slope (\%) & $0-10$ & $10-30$ & $30-60$ & $60<$ \\
\hline Suitability classes & S1 & S2 & S3 & N \\
\hline
\end{tabular}

Table 5. Slope suitability classes (Neameh, 2003)

\subsection{Water resources}

The suitability categories of this model were determined via the combination of three submodels of quality, quantity and distance from water sources (Figure 7). The distance from water sources suitability classes in livestock use are illustrated in Table 6 (Figure 8).

\begin{tabular}{l|cccc}
\hline Slope class (\%) & $0-10$ & $10-30$ & $30-60$ & $>60$ \\
\hline Suitability class & $0-3400$ & $0-3000$ & $0-1000$ & $\mathrm{~N}$ \\
S1 & $3400-5000$ & $3000-4800$ & $1000-3600$ & $\mathrm{~N}$ \\
S2 & $5000-6400$ & $4800-6000$ & $3600-4100$ & $\mathrm{~N}$ \\
S3 & $>6400$ & $>6000$ & $>4100$ & $\mathrm{~N}$ \\
N &
\end{tabular}

Table 6. Water resource distance and its suitability classes

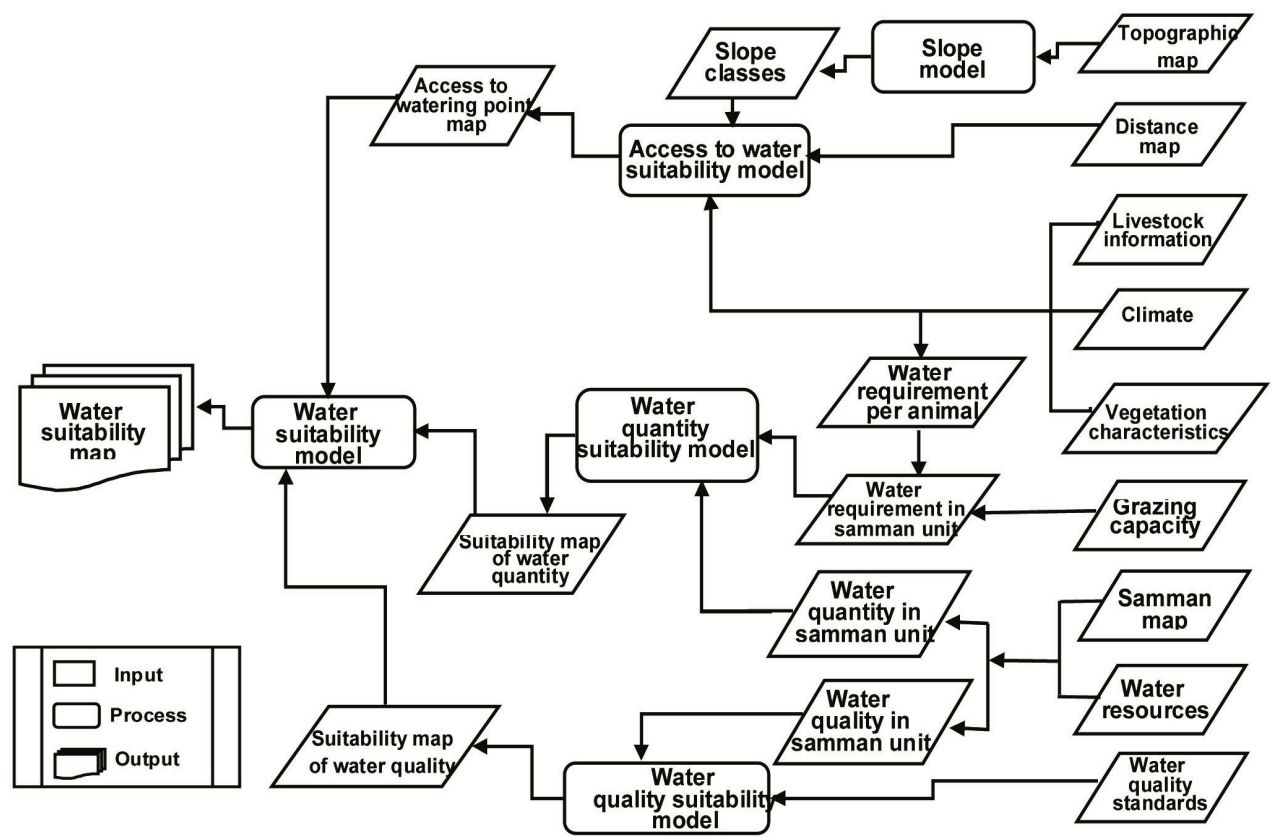

Figure 7. Model for classification of water resource suitability (Amiri, 2009a; b) 


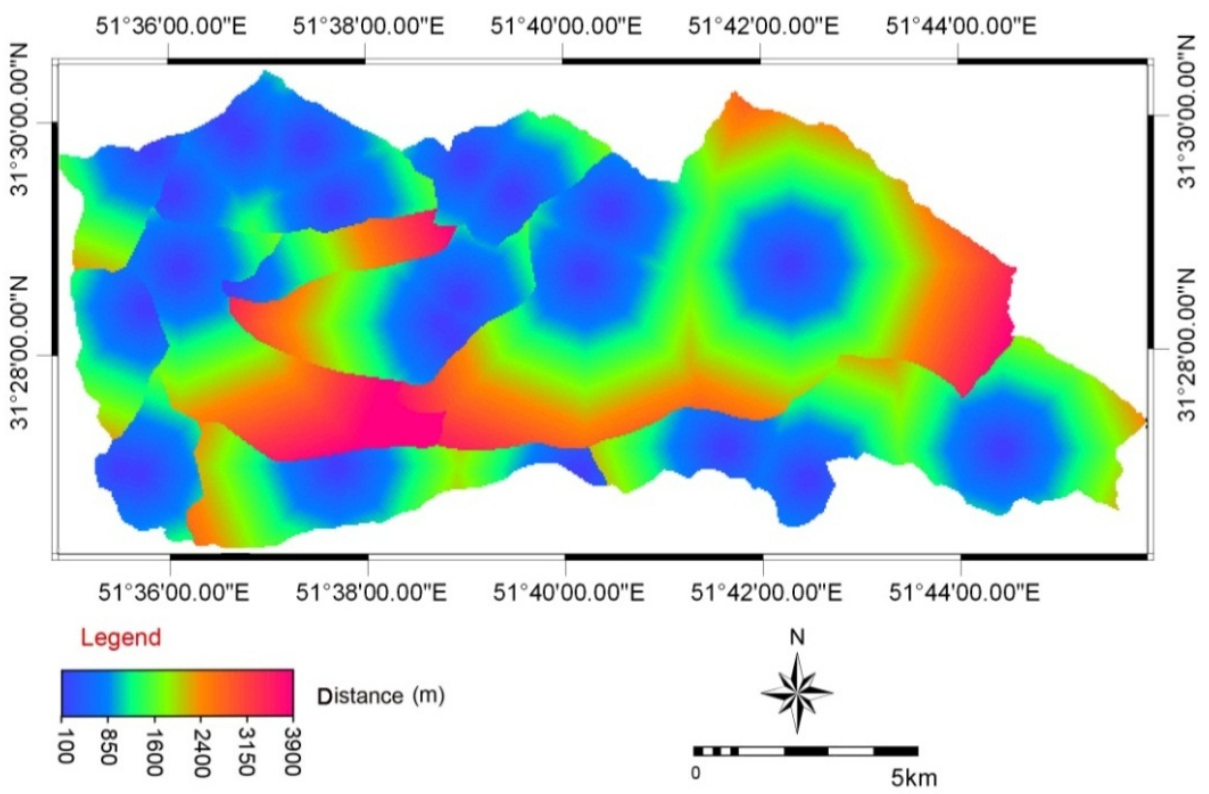

Figure 8. Water resource distance in Ghara-Aghch rangeland

Khan and Ghosh (1982) studied tolerance of goats and sheep to saltiness under difficult environmental conditions in the Rajasthan desert, and observed that the tolerance of the goats was higher than the sheep. The water suitability precincts of the region were classified based on Total Dissolved Salts in the water (TDS) (Table 7).

\begin{tabular}{|c|c|c|c|c|}
\hline \multirow{2}{*}{ Suitability class } & \multicolumn{4}{|c|}{ Total Dissolved Salts (TDS; ppm) } \\
\hline & S1 & S2 & S3 & $\mathrm{N}$ \\
\hline Sheep & $<3000$ & $3000-6000$ & $6000-10000$ & $>10000$ \\
\hline goats & $<3000$ & $5000-7000$ & $7000-10000$ & $>10000$ \\
\hline
\end{tabular}

Table 7. Water quality suitability classes for sheep and goats (Bagley et al 1997)

\subsection{Quantity of water sources}

Many factors affect the amount of water used by livestock which include the kind of livestock, the livestock's age and breed, the regions topography, available forage and quality of the forage, the grazing season, the quantity, quality and distance from water resources. King (1983) developed a formula (5) for the amount of water needed by African goats with an average weight of 37 kilograms:

$$
\text { a } 1 / \mathrm{kg}^{0.82} / \text { day }=\text { ? lit } / \text { day }
$$

In this formula ' $a$ ' is the coefficient which is to be calculated based on local investigations. The '?' is the amount of water needed by the livestock, and ' $\mathrm{kg}^{\prime}$ is the live weight of the 
livestock on the kilogram basis. Ferreira et al. (2002) calculated the amount of water needed by Merino breed sheep with an average weight of 50 kilograms via the following formula (6):

$$
37 \mathrm{ml} / \mathrm{kg}^{0.82}
$$

Therefore, based on all the factors involved in the calculation of the water needed in each Samman unit and information from local pastoral farmers (Formulas 5 and 6), the water needed for a mature sheep (Ghashghaei Turkish breed) was calculated as five liters per day and for a mature goat (Ghashghaei Turkish breed) it was estimated as four liters per day (Amiri, 2009b).

The grazing capacity map of each vegetation type was overlaid with the map of the Samman unit and via weight averaging based on the area of each Samman unit, the quantity of the water resources was determined and the number of permitted livestock (sheep and goats) was calculated for each Samman unit. The suitability categories were then determined by comparison of the available water in each Samman unit with the water needed by the livestock in each Samman unit (Table 8).

\begin{tabular}{llllll}
\hline Available water in pasture ration to livestock need (\%) & $>76$ & $51-75$ & $26-50$ & $<25$ \\
\hline Suitability classes & S1 & S2 & S3 & N \\
\hline
\end{tabular}

Table 8. Water resource suitability classes

\section{Results}

\subsection{Erosion sensitivity model}

The erosion sensitivity model on vegetation types showed that about $3.5 \%$ of the regions rangeland surface (254.25 hectares) was classified in as erosion Class II (low sedimentation intensity), 64\% (4585.98 hectares) as Class III (medium sedimentation intensity), and 32.4\% (2318.95 hectares) was classified as erosion Class IV (high sedimentation intensity). Furthermore, the results of suitability categories of soil sensitivity to erosion revealed that 4585.98 hectares $(64 \%)$ of the rangeland surface was classified in the S2 suitability category and 2572.84 hectares (36\%) was placed in the S3 suitability category. The map of suitability categories of the EPM model are shown in Figurer 9.

\subsection{Forage production and livestock grazing capacity}

The results of the suitability model on forage production of vegetation types in the study area under investigation are illustrated in Table 9. According to the forage production model, none of the vegetation types fall into the S1 suitability category. About 1352.46 hectares $(18.89 \%)$ of the rangeland fell into the S2 suitability category, around 4837.74 hectares $(67.57 \%)$ of the rangeland fell in the S3 suitability category on forage production, and finally 968.61 hectares $(10.8 \%)$ of the rangeland fell in the $\mathrm{N}$ suitability category (Figurer 10). The results on the livestock grazing capacity in the study area are shown in Table 10. 


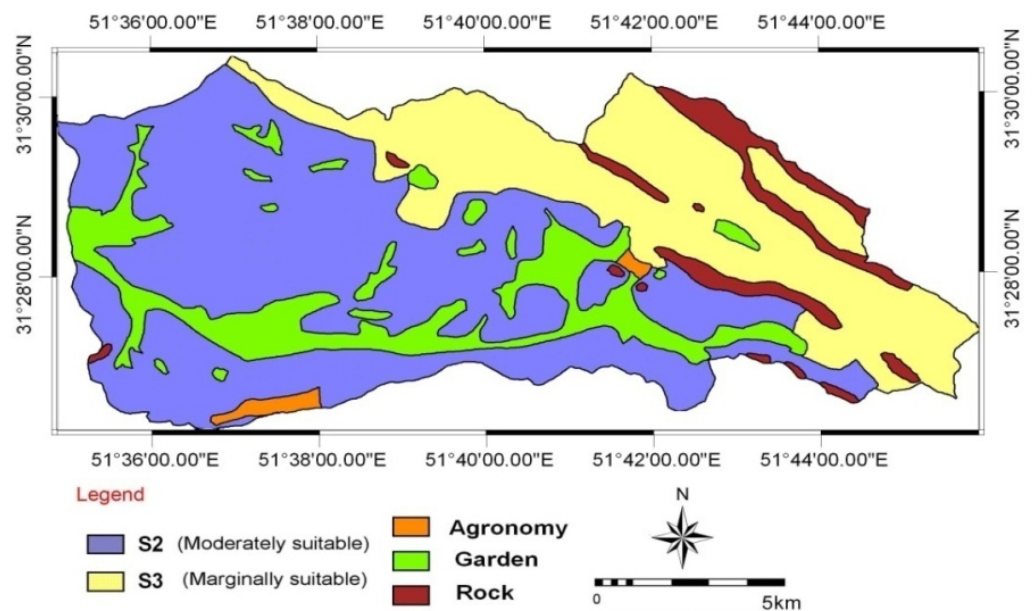

Figure 9. Erosion class properties in Ghara-Aghch

\begin{tabular}{|c|c|c|c|c|c|}
\hline \multirow{2}{*}{\multicolumn{2}{|c|}{ Number Vegetation type }} & \multicolumn{2}{|c|}{$\begin{array}{c}\text { Available forage based on } \\
\text { herd composition }(\mathrm{kg} / \mathrm{h})\end{array}$} & \multirow{2}{*}{$\begin{array}{l}\text { Ratio of available forage to } \\
\text { total production }\end{array}$} & \multirow{2}{*}{$\begin{array}{c}\text { Forage } \\
\text { suitability } \\
\text { classes }\end{array}$} \\
\hline & & sheep & goats & & \\
\hline 1 & Ag.tr & 88.9 & 31.8 & 31.7 & S2 \\
\hline 2 & Ag.tr-As.pa & 60.7 & 34.3 & 27.6 & S3 \\
\hline 3 & $\begin{array}{l}\text { Ag.tr-As.ca- } \\
\text { Da.mu }\end{array}$ & 66.6 & 23 & 27.7 & S3 \\
\hline 4 & $\begin{array}{l}\text { As.ad-Ag.tr- } \\
\text { Da.mu }\end{array}$ & 66.7 & 24.2 & 30.8 & S2 \\
\hline 5 & As.pa-Ag.tr & 58.2 & 22.4 & 25.8 & S3 \\
\hline 6 & $\begin{array}{l}\text { As.ly-Ag.tr- } \\
\text { Da.mu }\end{array}$ & 60 & 20.8 & 28.2 & S3 \\
\hline 7 & $\begin{array}{l}\text { As.ca-Br.to- } \\
\text { Co.cyl }\end{array}$ & 42.1 & 16.8 & 25.1 & S3 \\
\hline 8 & $\begin{array}{l}\text { As.br-Br.to- } \\
\text { Da.mu }\end{array}$ & 67.8 & 23.2 & 32.3 & S2 \\
\hline 9 & As.go-Co.cyl & 35.2 & 24.2 & 23.1 & S3 \\
\hline 10 & $\begin{array}{l}\text { As.pa-Co.cyl- } \\
\text { Da.mu1 }\end{array}$ & - & - & - & $\mathrm{N}$ \\
\hline 11 & As.cy-Fe.ov & 56.1 & 31.2 & 30.01 & S2 \\
\hline 12 & Br.to-As.pa & 58.5 & 19.8 & 30.2 & S2 \\
\hline 13 & Co.ba-As.go & 44.2 & 23.8 & 27.5 & S3 \\
\hline 14 & Co.ba-Sc.or & 33.9 & 19.5 & 23.3 & S3 \\
\hline 15 & $\begin{array}{l}\text { Fe.ov-Br.to- } \\
\text { As.za }\end{array}$ & 81.3 & 30.2 & 33.4 & S2 \\
\hline 16 & Ho.vi-Po.bu & 152 & 53.8 & 31.8 & S2 \\
\hline 17 & Br.to-Sc.or & 53.6 & 29.8 & 28.4 & S3 \\
\hline
\end{tabular}

Table 9. Suitability classes based on forage production and available forage in Ghareh Aghach [Since this type is classified in the $\mathrm{S} 3$ erosion suitability class and is of a poor condition with a downward trend it is unsuitable for livestock grazing] 


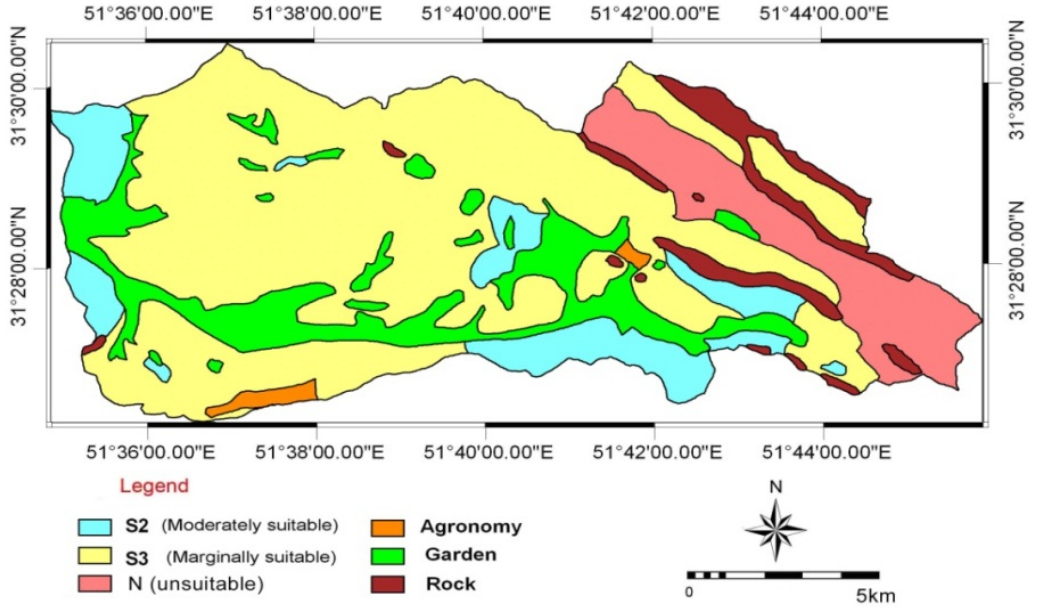

Figure 10. Suitability map of forage production at Ghara-Aghch

\begin{tabular}{|c|c|c|c|c|c|c|c|c|c|c|}
\hline \multirow[t]{2}{*}{ Number } & \multirow[t]{2}{*}{$\begin{array}{l}\text { Vegetation } \\
\text { type }\end{array}$} & \multicolumn{2}{|c|}{$\begin{array}{l}\text { Available } \\
\text { forage }(\mathrm{kg} / \mathrm{h})\end{array}$} & \multirow[t]{2}{*}{$\begin{array}{l}\text { Area } \\
\text { (h) }\end{array}$} & \multicolumn{2}{|c|}{$\begin{array}{l}\text { Daily forage } \\
\text { need }(\mathrm{kg})\end{array}$} & \multirow{2}{*}{$\begin{array}{l}\text { gazing } \\
\text { period } \\
\text { (day) }\end{array}$} & \multirow{2}{*}{$\begin{array}{l}\text { Livestock } \\
\text { grazing } \\
\text { capacity } \\
\text { (on AUM) }\end{array}$} & \multicolumn{2}{|c|}{$\begin{array}{l}\text { Livestock } \\
\text { grazing (number } \\
\text { of head) }\end{array}$} \\
\hline & & sheep & goats & & sheep & ${ }^{2}$ goats & & & sheep & goats \\
\hline 1 & Ag.tr & 88.9 & 31.8 & 122.77 & 1.36 & 1.165 & 120 & 95 & 67 & 35 \\
\hline 2 & Ag.tr-As.pa & 60.7 & 34.3 & 305.59 & 1.38 & 1.179 & 120 & 186 & 112 & 93 \\
\hline 3 & $\begin{array}{l}\text { Ag.tr-As.ca- } \\
\text { Da.mu }\end{array}$ & 66.6 & 23 & 898.36 & 1.4 & 1.19 & 120 & 500 & 356 & 180 \\
\hline 4 & $\begin{array}{l}\text { As.ad-Ag.tr- } \\
\text { Da.mu }\end{array}$ & 66.7 & 24.2 & 385.59 & 1.41 & 1.2 & 120 & 217 & 152 & 81 \\
\hline 5 & As.pa-Ag.tr & 58.2 & 22.4 & 162.77 & 1.44 & 1.234 & 120 & 79 & 55 & 30 \\
\hline 6 & $\begin{array}{l}\text { As.ly-Ag.tr- } \\
\text { Da.mu }\end{array}$ & 60 & 20.8 & 237.51 & 1.4 & 1.194 & 120 & 119 & 85 & 42 \\
\hline 7 & $\begin{array}{l}\text { As.ca-Br.to- } \\
\text { Co.cyl }\end{array}$ & 42.1 & 16.8 & 2029.68 & 1.49 & 1.272 & 120 & 700 & 477 & 279 \\
\hline 8 & $\begin{array}{l}\text { As.br-Br.to- } \\
\text { Da.mu }\end{array}$ & 67.8 & 23.2 & 116.2 & 1.42 & 1.217 & 120 & 64 & 46 & 23 \\
\hline 9 & $\begin{array}{l}\text { As.go-Co.cyl } \\
{ }^{1} \text { As.pa- }\end{array}$ & 35.2 & 24.2 & 362.66 & 1.54 & 1.315 & 120 & 125 & 69 & 70 \\
\hline 10 & $\begin{array}{l}\text { Co.cyl- } \\
\text { Da.mu }\end{array}$ & - & - & - & - & - & 120 & - & - & - \\
\hline 11 & As.cy-Fe.ov & 56.1 & 31.2 & 105.7 & 1.43 & 1.222 & 120 & 57 & 34 & 29 \\
\hline 12 & Br.to-As.pa & 58.5 & 19.8 & 373.11 & 1.55 & 1.322 & 120 & 158 & 113 & 56 \\
\hline 13 & Co.ba-As.go & 44.2 & 23.8 & 188.52 & 1.52 & 1.3 & 120 & 75 & 46 & 36 \\
\hline 14 & Co.ba-Sc.or & 33.9 & 19.5 & 499.07 & 1.63 & 1.397 & 120 & 145 & 87 & 73 \\
\hline 15 & $\begin{array}{l}\text { Fe.ov-Br.to- } \\
\text { As.za }\end{array}$ & 81.3 & 30.2 & 212.33 & 1.37 & 1.168 & 120 & 151 & 105 & 57 \\
\hline 16 & Ho.vi-Po.bu & 152 & 53.8 & 36.76 & 1.52 & 1.3 & 120 & 44 & 31 & 16 \\
\hline 17 & Br.to-Sc.or & 53.6 & 29.8 & 153.58 & 1.39 & 1.19 & 120 & 82 & 50 & 40 \\
\hline
\end{tabular}

Table 10. Livestock grazing capacity of vegetation types [1This type is unsuitable for livestock graze. ${ }^{2}$ The weight of the sheep (a livestock unit) was 50 kilograms and the average weight of the goats was 37 kilograms, $50 / 37=0.8$, as a result the ratio of each sheep to a goats in the region is 0.8$]$ 


\subsection{Suitability model of water resource quality}

The water resource quality sub-model was determined by examination of the effective factors on the water quality and by comparison with specific standards. Based on the water resources quality sub-model and considering the water quality, there were no limitation in the region in question, and the whole region fell within the S1 suitability category (Table 11).

\begin{tabular}{|c|c|}
\hline${ }^{\circ} \mathrm{N}$ & 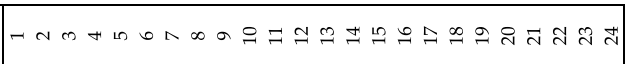 \\
\hline 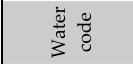 & 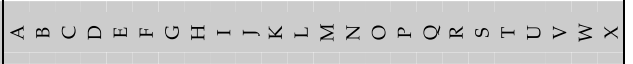 \\
\hline 䔍 & 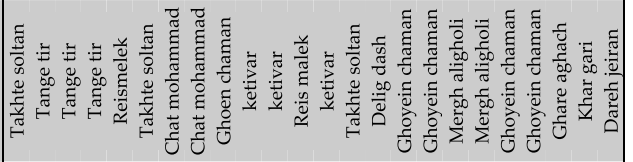 \\
\hline 觉 $\alpha$ 表 & 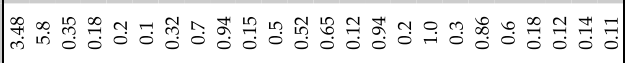 \\
\hline $\mid$\begin{tabular}{l|l}
$\mid \frac{5}{2}$ \\
$\frac{5}{3}$
\end{tabular} & 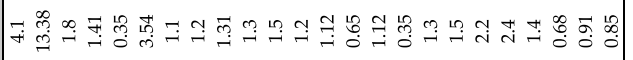 \\
\hline 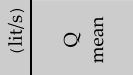 & 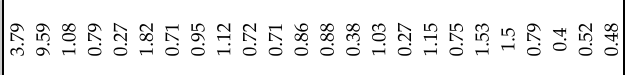 \\
\hline$\frac{7}{2}$ & 秉 \\
\hline 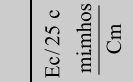 & 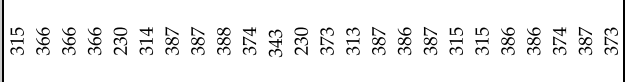 \\
\hline 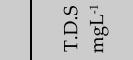 & 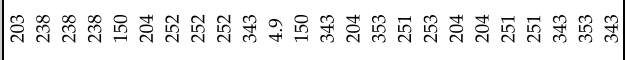 \\
\hline 癹 & 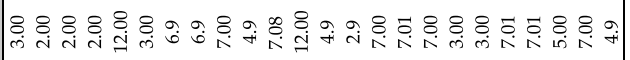 \\
\hline ¿ & 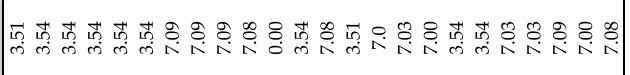 \\
\hline 童 & \%8:8\% \\
\hline \begin{tabular}{l|l}
0 \\
0
\end{tabular} & 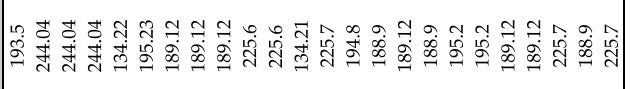 \\
\hline 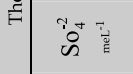 & 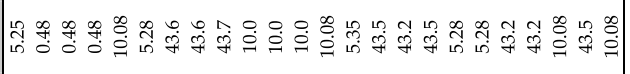 \\
\hline 筞 & 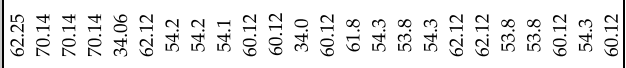 \\
\hline 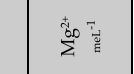 & 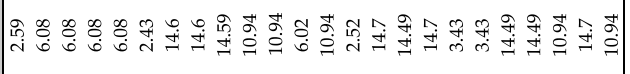 \\
\hline \pm & 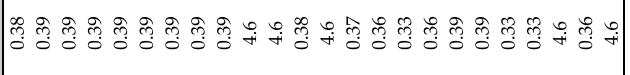 \\
\hline 索 & 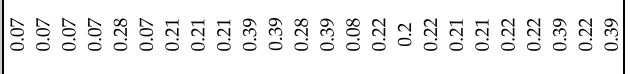 \\
\hline 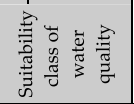 & \\
\hline
\end{tabular}

Table 11. Ghareh Aghach water resources quality and quantity 


\subsection{Suitability model of water resources quantity}

The results achieved from the sub-model on water resource's quantity are presented in Table 12. The results of the sub-model, revealed that there were no limitations on the amount of water in the Samman units in question and that all fell into the S1 suitability category.

\begin{tabular}{|c|c|c|c|c|c|c|c|}
\hline \multirow[t]{2}{*}{ Samman unit } & \multirow[t]{2}{*}{$\begin{array}{c}\text { water } \\
\text { content } \\
\text { (lit/day) }\end{array}$} & \multicolumn{2}{|c|}{$\begin{array}{c}\text { Carrying capacity in each } \\
\text { Samman unit (A head of } \\
\text { livestock in } 120 \text { day) } \\
\end{array}$} & \multicolumn{2}{|c|}{$\begin{array}{l}\text { Water need } \\
\text { (lit/day) }\end{array}$} & \multicolumn{2}{|c|}{$\begin{array}{c}\text { Suitability classes of } \\
\text { water quantity }\end{array}$} \\
\hline & & sheep & goats & sheep & goats & sheep & goats \\
\hline Catevar & 224640 & 389 & 122 & 1945 & 488 & S1 & S1 \\
\hline Chatemohammad & 143424 & 328 & 166 & 1640 & 664 & S1 & S1 \\
\hline Dalicdash & 88992 & 99 & 55 & 495 & 220 & S1 & S1 \\
\hline Darehgairan & 41472 & 249 & 143 & 1245 & 572 & S1 & S1 \\
\hline Ghare-aghach & 34560 & 125 & 84 & 625 & 336 & S1 & S1 \\
\hline Ghoeenchaman & 417312 & 107 & 81 & 535 & 324 & S1 & S1 \\
\hline Kargari & 44927 & 27 & 24 & 135 & 96 & S1 & S1 \\
\hline Marghalighole & 196992 & 326 & 192 & 1630 & 768 & S1 & S1 \\
\hline Raesmalek & 97632 & 258 & 152 & 1290 & 608 & S1 & S1 \\
\hline Taktesoltan & 517536 & 91 & 50 & 455 & 200 & S1 & S1 \\
\hline Tangetir & 990144 & 166 & 94 & 830 & 376 & S1 & S1 \\
\hline Total & 2797632 & 2165 & 1163 & 10825 & 4652 & S1 & S1 \\
\hline
\end{tabular}

Table 12. Quantity suitability of water resource in each Samman unit

\subsection{Distance from water resources suitability}

The results of the sub-modal on the distance from water resources suitability revealed that 6385.17 hectares of the rangeland area (89.2\%) fell in the S1 suitability category, 530.04 hectares $(7.4 \%)$ of the rangeland of the region in question fell into the S2 suitability category, and only 243.6 hectares $(3.4 \%)$ of the rangeland fell into the unsuitable $(\mathrm{N})$ category; in addition, no rangeland area fell into the S3 suitability category. The final outcome of the model on water resources is illustrated in Table 13. The region in question had no problems regarding the quantity and quality of the water resources; it was only the distance from the resources that mainly determined the suitability of the rangeland with respect to water resources.

\begin{tabular}{lc}
\hline \multirow{2}{*}{ Suitability classes } & Livestock grazing \\
\cline { 2 - 2 } S1 & Area (ha) \\
S2 & $6,385.17(89.2 \%)$ \\
S3 & $530.04(7.4 \%)$ \\
N & - \\
Total land area in study & $243.6(3.4 \%)$ \\
\hline
\end{tabular}

Table 13. Categorization of land area into suitability classes based on water resources model 


\subsection{Final application for livestock grazing}

The final outcome of the suitability model for livestock grazing was derived from the combination of three suitability sub-models involving soil sensitivity to erosion, forage production suitability, and the suitability of the water resources (Table 14).

\begin{tabular}{lcccc}
\hline Sub-model & S1 & S2 & S3 & N \\
Erosion & 0 & $4,078(57.0 \%)$ & $386(5.4 \%)$ & $2,696(37.6 \%)$ \\
Water Resources & 0 & $4,519(77.1 \%)$ & $859(12.0 \%)$ & $478(6.7 \%)$ \\
Forage production & 0 & $979(13.7 \%)$ & $5,211(72.8 \%)$ & $969(13.5 \%)$ \\
Integrated model & 0 & $1,126(15.7 \%)$ & $4,918(68.7 \%)$ & $1,116(15.6 \%)$ \\
\multicolumn{2}{l}{ Total land area in study $=\mathbf{7 , 1 5 9}$ ha } & & & \\
\hline
\end{tabular}

Table 14. Model-based categorization of land area into suitability classes

\section{Discussion}

Iran is the second largest country in the Middle East, but has limited natural resources such as fertile soil and water, resulting in limited opportunities to expand and/or intensify arable farming. Extensive animal husbandry, on the other hand, including nomadic, transhumant and sedentary forms, is widespread over the rangelands of the country. Rangelands and animal husbandry have been important in Iran for a very long time, as witnessed by the teachings of Zoroaster. More recently, many people have died in the defence of their rangelands after land nationalization, when only the right of use was at stake. The degree of importance attached to a specific rangeland area reflects its productivity, land scarcity and the availability of alternative sources of income. In Iran, as in most parts of the world, animal husbandry is the most productive use of semi-arid zones bordering the desert. However, overgrazing is a major problem in most of these areas. Therefore, the objectives of this paper, was to apply the concept of range inventory in the recognition and evaluation of potential and actual production for optimal utilization of this valuable natural resource for domestic livestock production.

The degree of importance attached to a specific rangeland area reflects its productivity, land scarcity and the availability of alternative sources of income. In Iran, as in other parts of the world, animal husbandry is the most productive use of semi-arid zones bordering deserts (Breman, De Wit, 1983; Reed, Bert, 1995). Farahpour et al. (2004) had estimated that 80 to $90 \%$ of the livestock production in Iran, equivalent to $168,000-180,000$ ton $y^{-1}$ of meat, was associated with the rangelands. Annual dry matter production of rangelands was estimated at more than ten million tons per hectare. In addition to forage production, mining, fuel wood collection, industrial use of rangeland, e.g. as source of medicinal plants and recreation are other rural enterprises in the rangelands of Iran.

Several researchers have reported that with livestock use and increasing grazing evenness (Forbes, Hodgson, 1985), will in the long term result in increased grazing capacity and livestock production (Abaye, Allen, Fontenot, 1994; Meyer, Harvey, 1985; Pringle, 
Landsberg, 2004), as well as increase plant diversity and income of the livestock-farmers. Livestock use can also enhance the consumption of poisonous and invasive plants by the livestock which are not sensitive to these species, and thus increase livestock production. For example, the leaves of plants such as Spurge and Larkspur are poisonous to cattle, but safe for sheep. Thus, sheep grazing will indirectly protect the cattle on the rangeland (Taylor, Ralphs, 1992). In the livestock use model adapted in this study no area fell in the $S_{1}$ suitability category (limitless), while the main part of the rangeland area (75.9\%) fell within the $S_{3}$ suitability category (with high limitation). Among all the factors considered in the lands surveyed, factors related to the vegetation and forage production were the most significant in decreasing the region's rangeland livestock use suitability.

In adapting the grazing suitability model for the rangeland due consideration was given to the climatic conditions, vegetation, soil, the status of the current utilization, and topography, and the factors were found to be effective to different degrees. Therefore, recognizing the factors effective in the model and determining the amount of limitations they impose was important for analyzing and assessing the rangeland. Arzani et al. (2006), Amiri (2009a) and Alizadeh et al. (2011) determined rangeland suitability for sheep and goats grazing using a livestock grazing model with the three components of forage production, water resources, and the soil sensitivity to erosion. In the present study via application of the FAO method (1991) the same three measures were employed to determine the final livestock grazing suitability model for the rangelands.

This research describes the use of a geographical information system (GIS) to construct land suitability models for livestock grazing in the Ghara-Aghch region, Iran. Based on FAO method and the source data, sub models were created focusing on three different themes: sensitivity of the soil to erosion, water resources and available forage. Models recognized the important factors affecting model suitability for livestock use of the rangeland, and also determining the kind and rate of the limitations and factors reducing the suitability with the aim of gaining an adequate plan for grazing. In assessing site considerations these general models identified wider resource management options and solved conflicts of rangeland allocation and livestock grazing between pastoral and rancher.

The results of the final suitability outcome of the model revealed (a) none at the S1 suitability category (unlimited), (b) 694.36 hectares (9.7\%) in the S2 suitability category (with minor limitation), (c) 5439.35 hectares $(75.9 \%$ ) in the S3 suitability category (major limitation), and (d) 1025.81 hectares (14.3\%) in the $\mathrm{N}$ suitability category (unsuitable). The most important reducing factors in model suitability model were: (a) land use and the vegetation cover (in relation to sensitivity of the soil to erosion), (b) the amount of the available forage in comparison with the total production and (c) the existence of less palatability plants among the pasture plants (forage production suitability). In general, no serious difficulty was observed for the livestock's water source, but in some areas the considerable distance from the water source and the precipitous slope resulted in a decrease or limitation in the graze suitability. Among all parameters studied, the specifications on vegetation and forage production were determined as the most significant factors in reducing the suitability of the rangeland for livestock grazing of sheep and goats. 


\subsection{Soil sensitivity of the erosion model}

The most important erosion reducing factors in the study area were determined by land and vegetation use. In the present study the factors affecting erosion were in compliance with reports by many similar studies. Factors of land use, surface cover, run off, and the current erosion in the region are among the most important factors influencing erosion in the GharaAghach region. Amiri (2009a) stated that the important factors in increasing erosion are soil sensitive to the erosion, unsuitable vegetation cover and the lack of proper management in land use. Neameh (2003) had also mentioned unsuitable land use (plowing the rangeland and changing them into farmlands) as the main factor in reducing the suitability of Roozeh Chay rangelands in Uromieh. The negative effects of over grazing and early grazing on the reduction of infiltration and increased run off (and consequently, increased erosion) were clearly specified.

\subsection{Water resources model}

The results of the study showed that the quantity (number of permanent water resources), quality and the distance from the water resources did not impose much limitations on the rangelands suitability for grazing livestock. However, the steep slopes along the livestock path to the water resources resulted in the formation of an 'unsuitability' category for livestock. Valentine (2001) reported on the importance of the slope factor in reaching the water resources, and declared that by increasing the slope the ability to graze decreases and increases the livestock demand to expend lots of energy. Steep slopes are not recommended for grazing, but instead they can be applied for other purposes (such as wild life and tourism). The quality and quantity of the water resources in the region did not impose any limitations. This study demonstrated that the slope factor in the rangelands of Semirom region was the major factor decreasing and limiting rangeland suitability with respect to the distance from water resources. The outcome of the research indicates the slope as the reducing and sometimes limiting factor in the range suitability. Hence, the slope factor is of considerable importance in determining the suitability of the pasture for grazing. As slope increases the water retention time on the ground decreases, the rate of penetration decreases, and the amount of water run-off increases. The possibility of retaining mature soils on steep slopes is reduced.

Grazing on steep slopes will cause movement of the soil and consequently, will make it difficult for plants to remain stable. Furthermore, the livestock will spend lots of energy in walking on the steep slopes (for grazing and reaching water sources) and as a result their function will decrease. Cook (1954) explained that on slopes of more than 60 degrees little forage is grazed. Amiri (2009b) and Gavili et al. (2011) defined the slopes with more than 60 percents as useless for all kinds of livestock, while Holechek et al. (1995) reported slopes of more than 60 percent, and Arzani et al. (2006) defined slopes of more than 60 percent as useless for livestock grazing. On such steep slopes wild animals would graze better than livestock. 


\subsection{Forage production model}

The major factors reducing suitability of the rangelands in the study area were improper use or exploitation limit, the existence of Class II and III plants in the forage combination, and the decrease in available forage for livestock. It must be noted that factors which cause reduction of proper use factor exploitation limit in the region, are themselves deemed as the reducing factors of the suitability of the rangeland. The effects of previous usage (changing the rangeland into farmlands and leaving them, or over grazing), the low vegetation cover, and the existence of low palatability class plants among the vegetation (perennial forbs and annual grasses) are among the factors reducing the suitability of forage production in the study area. Plowing rangelands with the aim of developing un-irrigated cultivation in the regions is one of the factors responsible for the destruction of the rangeland, although the annual rainfall allows for rain-watered cultivation. It must be noted that these rangelands with deep and good soils are among the best rangelands in the country. As the climatic conditions in the study area facilitates un-irrigated cultivation the region's rangeland has in the past been plowed and cultivated, wherever the soil depth and the slope were not limiting. During the early years of neglect of the un-irrigated-farms, the invader plants (most of the annual grasses and forbs) had become established in the region. The annual forbs and grasses make up a temporary vegetative ground cover (during the growing season), while for much of the year the ground has no vegetative cover and hence is defense-less against erosion. The present study revealed that changing the rangeland to rain-watered farms and neglecting them, over grazing, early grazing, low vegetation cover, and presence of fewer palatable species as the most important factors reducing suitability of the study area in terms of forage production. Amiri (2009a) had also observed low vegetative cover as among the most important factors in reducing production suitability of a region.

The results of the final range suitability model revealed that the most important factor in reducing the rangeland suitability of the study area was the low amount of the available forage in comparison to the total herbage production. It must be noted that other factors responsible for reducing the suitability of the region's rangeland include low vegetations cover, lack of proper vegetative ground cover to protect the surface soil, surface run-off, slope, the sensitivity of the soil to erosion, climatic conditions, plant combination, the condition and trend in vegetation types, over grazing, and finally invasion of the rangeland areas determine the suitability of the region's rangeland. Furthermore, an important factor in limiting grazing is the steep slope of the region (more than 60 degree).

Farahpour et al. (2004) reported that early and over grazing as the main causes of the reduction of the suitability of the rangelands of Shadegan in Isfahan, but in the Ghara Aghach district, due to the limitations imposed on early grazing by the Institute of the Natural Resources (I.N.R.) of Isfahan Province and Semirom City, early grazing was not the suitability limiting factor in the region's rangelands.

Guenther et al. (2000) in determining the suitability of a region in Australia noted the two factors of slope and water resources as the suitability limiting factors of rangeland for 
grazing cattle. Due to the existence of numerous permanent water resources in the GharaAghach rangelands, the water resources factor does not impose much limitation on the suitability of the rangeland of the region. However, the slope factor in reaching the water resources in limited areas of the region's rangeland was a suitability limiting factor. Fitumukiza (2004) on determining the suitability of the rangeland of the Gaza Province in Mozambique for cattle grazing, considered such parameters as rainy and growing seasons, soil characteristics, vegetative cover, the needed and available forage, reaching the water resources and slope, and expressed the major suitability limiting factors in the region's rangeland as: firstly, the lack of accessibility to the water resources; then, low palatability of the plant species, low production of the forage and the slope. It must be noted that the results reported by Guenther et al. (2000) and Fitumukiza (2004) were similar to that observed in the present study. Arzani et al. (2006) studied sheep grazing in four regions of Siahrood and Lar in the Alborz mountain range, Ardsetan in central area, and Dasht-e Bakan in Zagros region, and observed that in the Siahrood region, the variety of the poisonous plants, the steep slope, temporary water resource, and the components sensitive to erosion were the main factors limiting the suitability of the region. The factors limiting the suitability of the rangeland in Lar region in order of their importance were: the steep slope, the sensitivity of the soil to erosion, and the manner of exploiting the lands. The factors limiting the suitability of rangeland in the Ardedstan region were: low productivity, the existence of invasive plants, greater distance from the water resources, the manner of exploiting the lands, and the current erosion. In the Dasht-e Bakan region, the slope, distribution of the water resources, and lack of permanent water resources were the factors limiting the suitability of the rangeland for grazing sheep.

The outcome of the present study also showed that due to low productivity of palatable forage as a result of constant utilization of the rangeland, the shortage or lack of palatable plants on one hand and the existence of numerous un-palatable and thorny plants in the vegetation composition on the other, effective grazing of livestock in the rangeland will be limited.

\section{Conclusion}

Assessment of rangelands is an activity that frequently challenges those involved in the livestock industry, environmental protection, and in land and rangeland management. The main objectives of an integrated land, forage and livestock resources suitability assessment are to quantify the resource endowment, understand interrelationships between resource components, predict environmental impact, estimate livestock support capacity, and evaluate development options.

Geographic Information Systems (GIS) have experienced rapid growth in recent years. GIS is a technology using a computer programme which aids in managerial, policy and development decisions, primarily by modeling suitability of land and forage resources for planning livestock grazing, taking system complexity into account. 
In this chapter, recent developments of using GIS as a smart tool in supporting the ranchers and pasture owners for monitoring land suitability for livestock feeding purposes is challenged. This research aims at developing a module based on GIS for predicting the physical suitability of land for livestock feeding. It can help decision makers to monitoring the level of land suitability for livestock grazing. It gives clear indicator for the suitability of land and limitation factors to be applied to practical land management with greater success. This study was carried out on a regional scale to examine limitations and opportunities for extensive grazing. While we may present a comprehensive attitude towards extensive grazing, one should know that grazing is one of the uses readily available for rangelands. As FAO argues, different land units have different qualities for certain utilizations. As might be understood, rangelands' utilizations comprise certain qualities and criteria that the model must consider in assessing suitability. However, mixed livestock grazing could be substituted with single utilization in order to gain sustainability of these resources and gain ultimate but sustainable benefits.

\section{Author details}

Fazel Amiri

Corresponding Author

Spatial and Numerical Modeling Laboratory, Institute of Advance Technology (ITMA),

Faculty of Engineering, Universiti Putra Malaysia, Malaysia

Abdul Rashid B. Mohamed Shariff

Spatial and Numerical Modeling Laboratory, Faculty of Engineering,

Universiti Putra Malaysia, Malaysia

Taybeh Tabatabaie

Environnemental Science, Faculty of Engineering, Islamic Azad University Bushehr Branch, Iran

\section{Acknowledgement}

I dedicate this chapter to my mother, and to all people that contributed towards its successful completion.

\section{References}

Abaye, A., Allen, V., Fontenot, J., (1994). Influence of grazing cattle and sheep together and separately on animal performance and forage quality. Journal of Animal Science 72, 1013-1022.

Ahmadi, H., (2004). Applied geomorphology (Vol.1, water erosion). Tehran University Publication, Tehran, Iran.

Alizadeh, E., Arzani, H., Azarnivan, H., Mohajeri, A., Kaboli, S., (2011). Range Suitability Classification for Goats using GIS: (Case study: Ghareaghach Watershed- Semirom). Iranian Journal of Range and Desert Research 18, 353-371. 
Amiri, F., (2009a). A model for classification of range suitability for sheep grazing in semiarid regions of Iran. Journal of Livestock Research for Rural Development 21, 68-84.

Amiri, F., (2009b). A GIS model for determination of water resources suitability for goats grazing. African Journal of Agricultural Research 4, 014-020.

Amiri, F., (2010). Estimate of Erosion and Sedimentation in Semi-arid Basin using Empirical Models of Erosion Potential within a Geographic Information System. Air, Soil and Water Research 3, 37-44.

Amiri, F., Shariff, A.R.B.M., (2011). An Approach for Analysis of Integrated Components on Available Forage in Semi-Arid Rangelands of Iran. World Applied Sciences Journal 12, 951-961.

Arzani, H., Jangjo, M., Shams, H., Mohtashamnia, S., Fashami, M., Ahmadi, H., Jafari, M., Darvishsefat, A., Shahriary, E., (2006). A model for classification of range suitability for sheep grazing in Central Alborz, Ardestan and Zagros regions. Journal of Science and Technology of Agriculture and Natural Resources 10, 273-290.

Baniya, N., (2008). Land suitability evaluation using GIS for vegetable crops in Kathmandu Vally/Nepal, Agriculture and Horticulture. University of Berlin.

Barbari, M., Conti, L., Koostra, B., Masi, G., Guerri, F.S., Workman, S., (2006). The use of global positioning and geographical information systems in the management of extensive cattle grazing. Biosystems engineering 95, 271-280.

Bizuwerk, A., Peden, D., Taddese, G., Getahun, Y., (2005). GIS Application for analysis of Land Suitability and Determination of Grazing Pressure in Upland of the Awash River Basin, Ethiopia, International Livestock Research Institute (ILRI), Addis Ababa, Ethiopia.

Bizuwork, A., Taddese, G., Peden, D., Jobre, Y., Getahun, Y., (2006). Application of geographic information systems (GIS) for the classification of production systems and determination of grazing pressure in uplands of the Awash River Basin, Ethiopia. Ethiop. Vet. J. 10.

Breman, H., De Wit, C., (1983). Rangeland productivity and exploitation in the Sahel. Science 221, 1341-1347.

Coffey, L., (2001). Multispecies grazing. Appropriate Technology Transfer for Rural Areas (ATTRA).-www. attra. ncat. org.

Collins, M.G., Steiner, F.R., Rushman, M.J., (2001). Land-use suitability analysis in the United States: historical development and promising technological achievements. Environmental Management 28, 611-621.

Cook, C.W., (1954). Common use of summer range by sheep and cattle. Journal of Range Management 7, 10-13.

FAO, (1976). A framework for land evaluation. Food and Agriculture Organization of the United Nations, Soils Bulletin 32.FAO, Rome. .

FAO, (1983). Guidelines: land evaluation for rainfed agriculture. Food and Agriculture Organization of the United Nations, Soils Bulletin 52. Rome, Italy.

FAO, (1984). Land evaluation for forestry. Forestry Paper 48. Food and Agriculture Organization of the United Nations, Rome, Italy. 
FAO, (1985). Guidelines: land evaluation for irrigated agriculture. Food and Agriculture Organisation of the United Nation, Rome.

FAO, (1991). Guidelines: land evaluation for extensive grazing, Issue 58 of FAO soils bulletin. Food \& Agriculture Org., 158 pp.

FAO, (2002). Agricultural drainage water management in arid and semi-arid areas. Food and Agriculture Organization of United Nations., Rome.

FAO, (2007). Land evaluation Towards a revised framework Food and Agriculture Organization of the United Nations., Rome, Italy.

Farahpour, M., Van Keulen, H., Sharifi, M., Bassiri, M., (2004). A planning support system for rangeland allocation in Iran with case study of Chadegan Sub-region. The Rangeland Journal 26, 225-236.

Ferreira, A., Hoffman, L., Schoeman, S., Sheridan, R., (2002). Water intake of Boer goats and Mutton merinos receiving either a low or high energy feedlot diet. Small Ruminant Research 43, 245-248.

Fitumukiza, D.M., (2004). Evaluating rangeland potentials for cattle grazing in a mixed farming system, International institute for geo-information science and earth observation. ITC, Netherlands.

Forbes, T., Hodgson, J., (1985). The reaction of grazing sheep and cattle to the presence of dung from the same or the other species. Grass and Forage Science 40, 177-182.

Gavili, E., Ghasriani, F., Arzani, H., Vahabi, M., Amiri, F., (2011). Determine water resources accessibility for sheep grazing by GIS technology (Case study: Feraidun Shahr rangeland in Isfahan Province). Journal of Applied RS and GIS Technology in Natural Resource Science 1, 89-99.

Guenther, K.S., Guenther, G.E., Redick, P.S., (2000). Expected-use GIS maps. Rangelands 22, 18-20.

Guo, Z.G., Liang, T.G., Liu, X.Y., Niu, F.J., (2006). A new approach to grassland management for the arid Aletai region in Northern China. The Rangeland Journal 28, 97-104.

Heady, H.F., (1975). Rangeland management. McGraw-Hill New York.

Holechek, J.L., Pieper, R.D., Herbel, C.H., (1995). Range management: principles and practices. Prentice-Hall, USA, 526 pp.

Hopkins, L.D., (1977). Methods for generating land suitability maps: a comparative evaluation. Journal of the American Institute of Planners 43, 386-400.

Javadi, S., Arzani, H., Farahpour, M., Zahedi, A., (2008). Evaluating Rangeland Suitability for Camel Grazing Using GIS (Case study: Tabashalvan range). Rangeland 2, 46-62.

Khan, M., Ghosh, P., (1982). Comparative physiology of water economy in desert sheep and goats, Proceedings of the 3rd International Conference on Goat Production and Disease, Dairy Goat Publishing Co., Scottsdale, USA.

King, J.M., (1983). Livestock water needs in pastoral Africa in relation to climate and forage. International Livestock Centre for Africa, Addis Ababa, Ethiopia.

Luginbuhl, J., Green Jr, J., Poore, M., Conrad, A., (2000). Use of goats to manage vegetation in cattle pastures in the Appalachian region of North Carolina. Sheep \& Goat Research Journal 16, 124-135. 
Meyer, H.H., Harvey, T., (1985). Multispecies livestock systems in New Zealand. In: Baker, F.H.J., R.K. (Ed.), Proceedings of a conference on multispecies grazing; June 25-28 Winrock International Institute for Agricultural Development, Morrilton, Ark. (USA), pp. p. 84-92.

Milner, C., Hughes, R.E., Gimingham, C., Miller, G., Slatyer, R., (1968). Methods for the Measurement of the Primary Production of Grassland. International Biological Programme (London and Oxford and Edinburgh). p.70, 70 pp.

Neameh, B., (2003). Land evaluation for Land Use Planning with especial attention to sustainable fodder production in the Rouzeh Chai catchment of Orumiyeh area, Iran. MS unpublished Thesis, International Institute for Geo-information Science and Earth Observation., Nederland. ITC, Netherlands, pp. 95.

Pringle, J.H., Landsberg, J., (2004). Predicting the distribution of livestock grazing pressure in rangelands. Austral Ecology 29, 31-39.

Rafahi, H.G., (2004). Wind erosion and conservation. Tehran University Publication, Tehran, Iran, $671 \mathrm{pp}$.

Reed, J., Bert, J., (1995). The role of livestock in sustainable agriculture and natural resource management. Livestock and sustainable nutrient cycling in mixed farming systems of sub-Saharan Africa 2, 461-470.

Smith, A.D., (1965). Determining common use grazing capacities by application of the key species concept. Journal of Range Management 18, 196-201.

Sonneveld, M.P.W., Hack-ten Broeke, M.J.D., van Diepen, C.A., Boogaard, H.L., (2010). Thirty years of systematic land evaluation in the Netherlands. Geoderma 156, 84-92.

Taylor, J., CA, Ralphs, M., (1992). Reducing livestock losses from poisonous plants through grazing management. Journal of Range Management 45, 9-12.

Thornton, P., Herrero, M., (2001). Integrated cropâ€“livestock simulation models for scenario analysis and impact assessment. Agricultural Systems 70, 581-602.

Vallentine, J.F., (2001). Grazing management. Elsevier, 659 pp.

Venkataratnam, L., (2002). Remote sensing and GIS in agricultural resources management., First National Conference on Agro-Informatics, INSAIT. 